\title{
Коллекция колыбелей Национального музея Тувы как этнокультурное наследие тувинцев
}

\author{
Майя О. Дыртык-оол, Анна О. Дыртык-оол
}

Национальный музей им. Алдан-Маадыр Республики Тыва, Российская Федерация

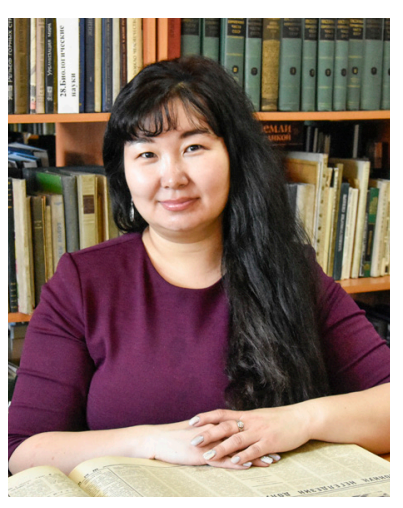

В статье анализируются проблемы хранения и популяризации таких предметов тувинского быта, как колыбели - кавай. В качестве источниковой базы исследования выступила коллекция колыбелей, хранящаяся в фондах Национального музея Тувы - 33 единицы, документация музея, архивные фотографии.

Традиционными источниками поступления колыбелей являются экспедиции сотрудников музея, отбор предметов и закупка на местах, поступления от частных лии, с выставок. Наиболее плодотворными для приобретения были 1950-1960-е г2., когда в Туве происходил массовый переход на оседлый образ жизни. В цзелом коллекция пополнялась с 1954 по 2015 г. Представлена сводная информация об истории поступления каждой колыбели, даны описания, аннотации, имена мастеров и пр. имеющиеся подробности. Но на сегодня имеется карточки с научным описанием только для 14 колыбелей.

Отмечается использование комплексного подхода к созданию экспозиций с использованием колыбелей. Они вписаны в реконструкции традиционных типов жилищ с полным

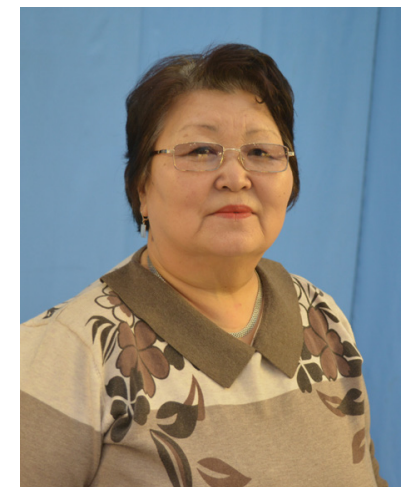
внутренним убранством. Кавай - важный элемент для культурно-просветительной работы музея, в том числе для детей и молодежи.

Ключевые слова: Национальный музей Тувы; Тува; тувинцы; детство; этнография детства; колыбель; музейная коллекция

\section{Для цитирования:}

Дыртык-оол М. О., Дыртык-оол А. О. Коллекция колыбелей Национального музея Тувы как этнокультурное наследие тувинцев [Электронный ресурс] // Новые исследования Тувы. 2019, № 2. URL: https://nit.tuva.asia/nit/ article/view/848 (дата обращения: дд.мм.гг.). DOI: 10.25178/nit.2019.2.8

Дыртык-оол Майя Оюновна - старший научный сотрудник отдела истории Национального музея им. Алдан-Маадыр Республики Тыва. Адрес: 667000, Россия, г. Кызыл, ул. Титова, д. 30. Тел.: +7 (394-22) 3-06-56. Эл. адрес: dyrtyk-ool@yandex.ru ORCID ID: 0000-00024039-6658

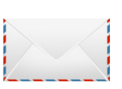

Дыртык-оол Анна Оюновна - кандидат исторических наук, доцент, заведующая отделом истории Национального музея им. Алдан-Маадыр Республики Тыва. Адрес: 667000, Россия, г. Кызыл, ул. Титова, д. 30. Тел.: +7 (394-22) 3-06-56. Эл. адрес: annaojun@yandex.ru ORCID ID:0000-0002-5899-9721

Dyrtyk-ool Maya Oyunovna, Senior Research Fellow, Department of History, Aldan-Maadyr National Museum of the Republic of Tuva. Postal address: 30 Titov St., 667000 Kyzyl, Russian Federation. Tel.: +7 (394-22) 3-06-56. E-mail: dyrtyk-ool@yandex.ru

Dyrtyk-ool Anna Oyunovna, Candidate of History, Associate Professor and Head, Department of History, Aldan-Maadyr National Museum of the Republic of Tuva. Postal address: 30 Titov St., 667000 Kyzyl, Russian Federation. Tel.: +7 (394-22) 3-06-56. E-mail: annaojun@yandex.ru 


\title{
The cradle collection at the National Museum of Tuva as Tuvan ethnocultural heritage
}

\author{
Maya O. Dyrtyk-ool, Anna O. Dyrtyk-ool \\ Aldan-Maadyr National Museum of the Republic of Tuva, Russian Federation
}

\begin{abstract}
The article looks at preservation and popularization of the kavai, a Tuvan cradle. This popular element of everyday culture of Tuvans has been studied through the cradle collection at the National Museum of the Republic of Tuva, which includes 33 objects, as well as archival photos and museum documents.

The cradles entered the collection in numerous ways - some were selected and acquired during the expeditions organized by museum staff, some came as gifts from private individuals or exhibitions. The acquisition peaked in the 1950s and 1960s, when Tuvans experienced mass transition from nomadic to settled style of living. Having been started in 1954, the collection has seen its last acquisition so far in 2015. The article presents consolidated information on the history of each object in the collection, including its brief annotation, description, acquisition data, creator's name, etc. As of today, full metadata is available for only 14 cradles.

When featured on an exposition, cradles are often part of a reconstruction of a traditional dwelling with full interior decoration. The kavai, used in this comprehensive context, has become an important element of the museum's cultural work, including that with children and the youth.
\end{abstract}

Keywords: National Museum of the Republic of Tuva; Tuvans; childhood; ethnography of childhood; cradle; museum collection

\section{For citation:}

Dyrtyk-ool M. O. and Dyrtyk-ool A. O. The cradle collection at the National Museum of Tuva as Tuvan ethnocultural heritage. The New research of Tuva. 2019, № 2. URL: https://nit.tuva.asia/nit/article/view/848 (access date ...). DOI: 10.25178/nit.2019.2.8

\section{Введение}

Пространство музея дает возможность для функционирования традиций культуры, для передачи опыта от предков к потомкам (Шелегина, 2014: 61; Смелякова, 2009: 103). Это можно рассмотреть на примере такого элемента этнографии - этнографии детства, как колыбели.

В связи с этим получают особую актуальность и интерес исследования истории комплектования коллекции колыбелей как элемента тувинской этнической культуры Национального музея им. АлданМаадыр Республики Тыва (НМ РТ) и форм ее популяризации.

Согласно Уставу Международного совета музеев (International Council of Museums, сокр. англ. ICOM), членом которого является НМ РТ, музей призван служить обществу, в том числе заниматься приобретением, хранением, использованием, популяризацией и экспонированием артефактов (Устав Международного совета ..., Электр. ресурс). Такие исторические предметы как кавай, вышедшие из повседневного употребления с середины XX в., свидетельствуют о традициях и обычаях тувинцев, которые связаны с детьми, отношением взрослых к детям и тому, как проходило детство в традиционной культуре. По словам Е. Н. Мастеницы, эти музейные предметы ценны как артефакты и как «творение рук человеческих (Мастеница, 2002: 329).

Цель данной статьи - анализ форм музейной деятельности по хранению и популяризации тувинских колыбелей. Для осуществления поставленной цели будут решаться задачи: определение путей формирования коллекции колыбелей в НМ РТ и вклада в него фондообразователей, анализ музейной документации, представляющей формы популяризации колыбелей как этнокультурного наследия тувинцев.

В качестве источниковой базы исследования выступила коллекция колыбелей, хранящаяся в фондах НM РТ, документация музея, с которой авторы имеют возможность непосредственно работать, а также фотографии первого профессионального фотографа Тувы и первого директора музея В. П. Ермолаева (инвентарные номера книги поступлений: КП 11286/1-402; КП 11286/1-805), на которых запечатлены колыбели в условиях их ежедневного использования. В работе использован сравнительный метод, 
НОВЫЕ ИССЛЕДОВАНИЯ ТУВЫ

www.nit.tuva.asia

позволяющий сопоставлять различные источники поступления в музеи, выявлять сходство или различия колыбелей. Типологический метод исследования позволяет систематизировать и классифицировать коллекцию колыбелей, показать этапы становления и развития этнографических коллекций, в состав которых входят колыбели.

\section{История формирования коллекции}

Во многих музеях России, в том в Российском этнографическом музее, Красноярском краевом краеведческом музее, Минусинском региональном краеведческом музее им. Н. М. Мартьянова, музее «История и материальная культура народов Центральной Азии» исторического факультета Тувинского государственного университета и в некоторых школьных музеях Тувы, хранятся и экспонируются тувинские колыбели. Они сдавались учеными и путешественниками, посещавшими Туву на рубеже XIX-XX вв. (Ф. Я. Коном, В. Тугариновым, Г. П. Сафьяновым и др., см.: Дыртык-оол, 2014: 54-57).

Самая большая коллекция колыбелей хранится в НМ РТ - 33 единицы. Традиционными источниками поступления в музей этнографических предметов, в том числе колыбелей, являются экспедиции сотрудников музея, отбор предметов и закупка на местах, поступления от частных лиц, с выставок.

1950-1960-е гг. были наиболее плодотворными по приобретению этнографических предметов, среди которых встречались колыбели. С середины XX в. в Туве происходят крупные перемены в жизни бывших кочевников - массовый переход на оседлый образ жизни. «Переход на оседлость был связан не только с резкой сменой традиционного образа жизни, изменениями в бытовой культуре, но и касался всей системы ценностей, основанной на традиционном мировоззрении, всей духовной культуры народа» (История Тувы, 2016: 62) (фото 1).

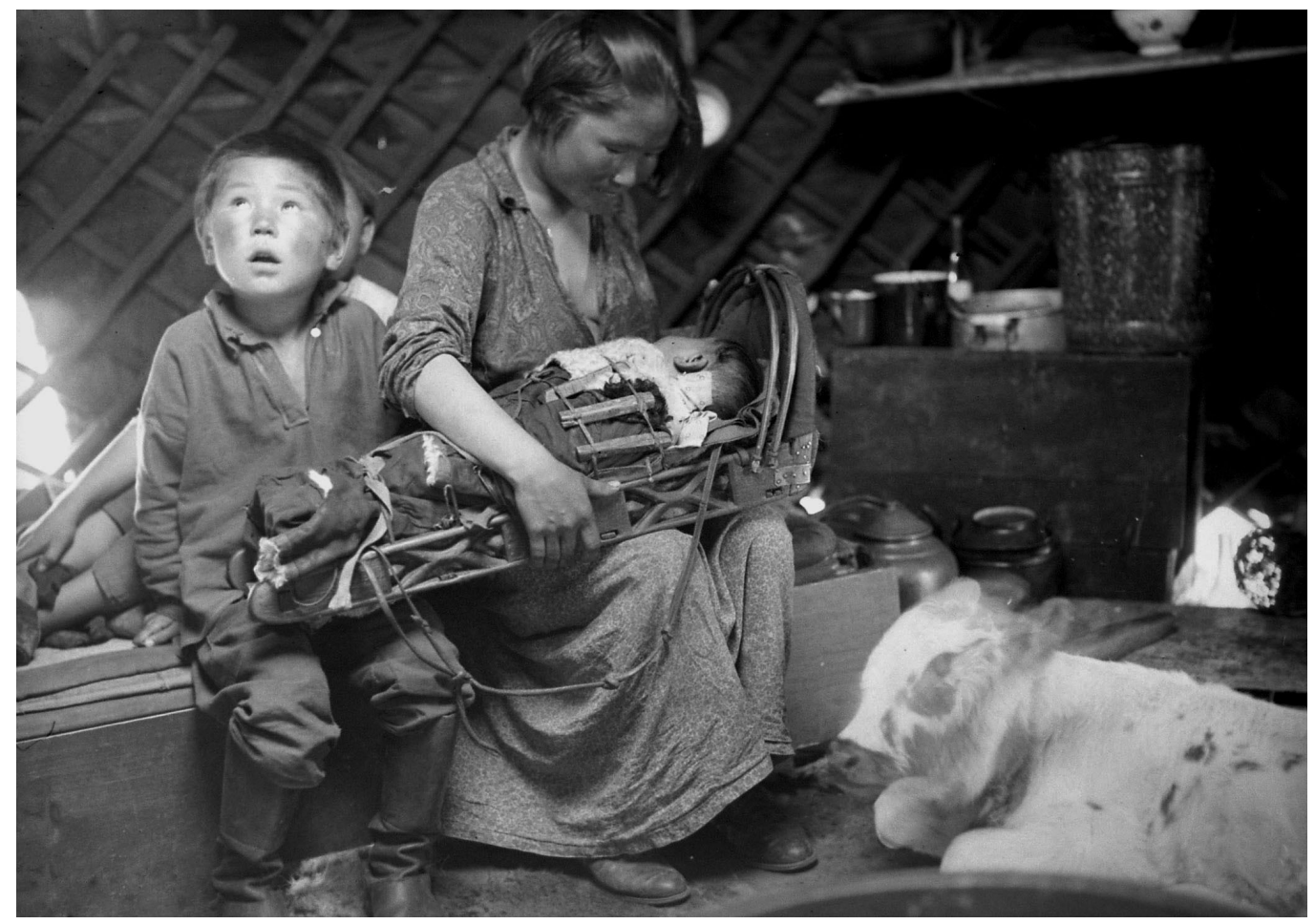

Фото 1. Тувинка с детьми, младший - в колыбели (КП 112861-402). Зыбка деревянная, ребенок привязан в ней ремешками. Фото В. П. Ермолаева, с. Ээрбек, 1930 г.

Photo 1. A Tuvan woman with children, the youngest one in his cradle (KP 112861-402).

The cradle is made of wood, with the baby fixed there with straps. Photo by V. P. Yermolayev, village Eerbek, 1930.

Основные хронологические рамки приобретенных вещей и зафиксированных в книгах поступлений 1954-2015 гг. В таблице 1 показана информация о формировании коллекции кавай основного фонда (20 единиц), в таблице 2 - научно-вспомогательного фонда (5 единиц). Причиной включения колыбелей в научно-вспомогательный фонд является его плохая сохранность и отсутствие его в среде бытования, т. е. предмет - новодел. 6 безномерных колыбелей хранятся в фондах. 2 колыбели имеют инвентарные номера - Д.225, Д.108, один из них экспонируется в Туранском филиале. 
Таблица 1. Сведения о поступлениях колыбелей в коллекцию основного фонда (Национального музея Тувы (1954-2007 г2.) Table 1. Cradles in the main collection of the National Museum of the Republic of Tuva (acquired 1954-2007)

\begin{tabular}{|c|c|c|c|c|}
\hline $\begin{array}{l}\text { Номер по } \\
\text { КП }\end{array}$ & $\begin{array}{c}\text { Год } \\
\text { поступления }\end{array}$ & ФИО сдатчика & $\begin{array}{c}\text { Место } \\
\text { приобретения }\end{array}$ & Источники поступлений \\
\hline 1160 & 1954 & - & - & - \\
\hline 3114 & 1958 & $\begin{array}{c}\text { Принадлежала 4-летней девочке } \\
\text { Хертек Хорлуу Мандан. Родилась в } \\
1954 \text { г. в с. Кара-Холь } \\
\text { Бай-Тайгинского района } \\
\end{array}$ & $\begin{array}{c}\text { п. Тээли } \\
\text { Бай-Тайгинского } \\
\text { района }\end{array}$ & $\begin{array}{l}\text { Сбор музейных сотрудников во } \\
\text { время командировки. Закупка. }\end{array}$ \\
\hline $4280 / 8$ & 1964 & - & $\begin{array}{c}\text { п. Кунгуртуг } \\
\text { Тере-Хольского } \\
\text { района }\end{array}$ & $\begin{array}{c}\text { Сбор музейных сотрудников } \\
\text { С. Ч. Уроякова и Т. М. Скаковой } \\
\text { во время этнографической } \\
\text { экспедиции }\end{array}$ \\
\hline 4421 & 1966 & - & - & $\begin{array}{c}\text { Сбор музейного сотрудника } \\
\text { С. М. Биче-оол в результате } \\
\text { командировки }\end{array}$ \\
\hline 5823 & 1973 & - & Тандинский район & $\begin{array}{c}\text { Сбор сотрудников Кочетовского } \\
\text { филиала }\end{array}$ \\
\hline 6505 & 1976 & Ондар Тигрин & $\begin{array}{c}\text { с. Чал-Кежи } \\
\text { Тандынского } \\
\text { кожууна }\end{array}$ & \\
\hline 7804 & 1981 & Аракчаа & г. Туран & \\
\hline 8016 & 1982 & Ч. С. Монгуш & $\begin{array}{c}\text { с. Барлык Барун- } \\
\text { Хемчикского } \\
\text { района }\end{array}$ & Закупка \\
\hline $8946 / 1 ; 2$ & 1984 & Намзырай Бора-Хоевна Лаахово & $\begin{array}{c}\text { с. Морен } \\
\text { Эрзинского района }\end{array}$ & Сбор отдела фондов; закупка \\
\hline 8947 & 1984 & Калдар Барзановна Монгуш & $\begin{array}{c}\text { С. Межегей } \\
\text { Тандынский } \\
\text { района }\end{array}$ & $\begin{array}{c}\text { Сбор музейного сотрудника } \\
\text { Е. Ш. Бай-Кара; закупка }\end{array}$ \\
\hline $8960 / 1,2$ & 1983 & $\begin{array}{c}\text { Александра Дензин-ооловна } \\
\text { Монгуш }\end{array}$ & & \\
\hline 9804 & 1990 & $\begin{array}{c}\text { Наталья Васильевна Оюн. } \\
\text { Легенда: колыбель была сделана } \\
\text { в } 1957 \text { г. мастером Маадыром } \\
\text { Янчатовичем Кыргысом } \\
\text { для родственницы Хорлуу } \\
\text { Сонгараковны Кыргыс }\end{array}$ & п. Хову-Аксы. & Закупка \\
\hline $10033 / 2$ & 1992 & Д. М. Дадар-оол & $\begin{array}{c}\text { Сут-Хольский } \\
\text { район }\end{array}$ & Закупка \\
\hline $10086 / 17$ & 1993 & & $\begin{array}{c}\text { Дзун-Хемчикский } \\
\text { район }\end{array}$ & $\begin{array}{c}\text { В. К. Пюрюна, зав. Чаданским } \\
\text { филиалом }\end{array}$ \\
\hline $10133 / 4$ & 1993 & Хуваалдай Ческеевна Баран & $\begin{array}{c}\text { с. Адыр-Кежик } \\
\text { Тоджинского } \\
\text { района } \\
\end{array}$ & $\begin{array}{c}\text { Сбор научного сотрудника музея } \\
\text { Л. М. Салчак; закупка }\end{array}$ \\
\hline $10184 / 1 ; 2$ & 1993 & & Тандинский район & $\begin{array}{c}\text { Сбор В. С. Оюна, зав. } \\
\text { Кочетовским филиалом }\end{array}$ \\
\hline 10626 & 2002 & $\begin{array}{c}\text { Народный мастер Маадырбай } \\
\text { Санчайевич, } 1916 \text { г. р. }\end{array}$ & $\begin{array}{c}\text { с. Хандагайты } \\
\text { Овюрского района }\end{array}$ & $\begin{array}{c}\text { Сбор сотрудника музея } \\
\text { К. Ш. Монгуш }\end{array}$ \\
\hline $10749 / 68$ & 2003 & $\begin{array}{c}\text { Мастер изготовитель Сундуй-оол } \\
\text { Монгушевич Арандол }\end{array}$ & $\begin{array}{c}\text { Тоджинский } \\
\text { кожуун }\end{array}$ & $\begin{array}{c}\text { Сбор научного сотрудника } \\
\text { Л. К. Монгуш } \\
\end{array}$ \\
\hline $11218 / 1$ & 2007 & $\begin{array}{c}\text { Колыбель была изготовлена } \\
\text { примерно 1956-1957 гг. мастером } \\
\text { Сарыг-оолом Сергеевичем Буярай } \\
\text { (монг. фамилия). Родился } 15 \\
\text { января } 1939 \text { г. в п. Кунгуртуг } \\
\text { Тере-Хольского кожууна. }\end{array}$ & $\begin{array}{c}\text { с. Кунгуртуг } \\
\text { Тере-Хольского } \\
\text { района }\end{array}$ & $\begin{array}{c}\text { Приобрел для музея научный } \\
\text { сотрудник Государственного } \\
\text { музея Востока В.А.Кореняко. }\end{array}$ \\
\hline \multicolumn{5}{|c|}{ Всего 20 ед. } \\
\hline
\end{tabular}




\section{НОВЫЕ ИССЛЕДОВАНИЯ ТУВЫ}

www.nit.tuva.asia

Первый кавай поступил в музей в 1954 г. К сожалению, в КП №1 отсутствуют важные для атрибуции сведения. Интересен сбор в Бай-Тайгинском районе. Кавай приобретен от 4-летней владелицы в 1958 г. с ее согласия (фото 2). С середины XX в. многие детские предметы уже не использовались в быту. Все приобретенные музеем каваи были изъяты из среды бытования.

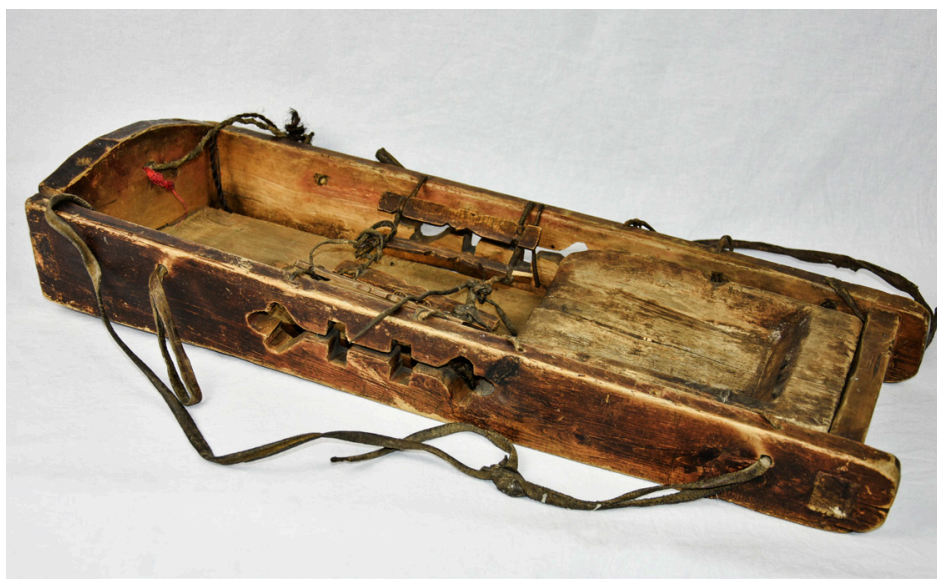

Фото 2. Детская колыбель (КП 3114). Сбор музейных сотрудников в n. Тээли Бай-Тайгинском кожууне 1958 г. Фото А. Д. Куулар, 2019 г. Photo 2. A cradle (KP 3114). Museum staff assembling at settlement Teeli, Bay-Tayga kozhuun, 1958. Photo by A. D. Kuular, 2019.

По результатам полевых командировок или этнографических экспедиций фонды музея пополнили сотрудники музея Т. М. Скакова, С. М. Биче-оол, Е. Ш. Байкара. Сборы на местах производились заведующими Кочетовского, Алдан-Маадырского и ДзунХемчикского филиалов. Если предмет имел репрезентативный вид, т.е. хорошую сохранность, наличие каких-либо более полных деталей, то музей закупал его. Они собирались почти во всех районах Тувы, даже в отдаленных (например, в Тере-Хольском).

К сожалению, на всех колыбелях, за исключением троих, отсутствуют сведения о дате изготовления и мастере. Одну колыбель изготовил знаток быта восточных оленеводов С. М.Арандол (фото 3). Этот новодел сделан по традиционной технологии.

К сожалению, многие колыбели во время документирования недостаточно аннотированы: не указаны фамилии мастера, время изготовления и использования, место их бытования. Мы не можем объяснить семантику того или иного узора или орнамента на предметах.

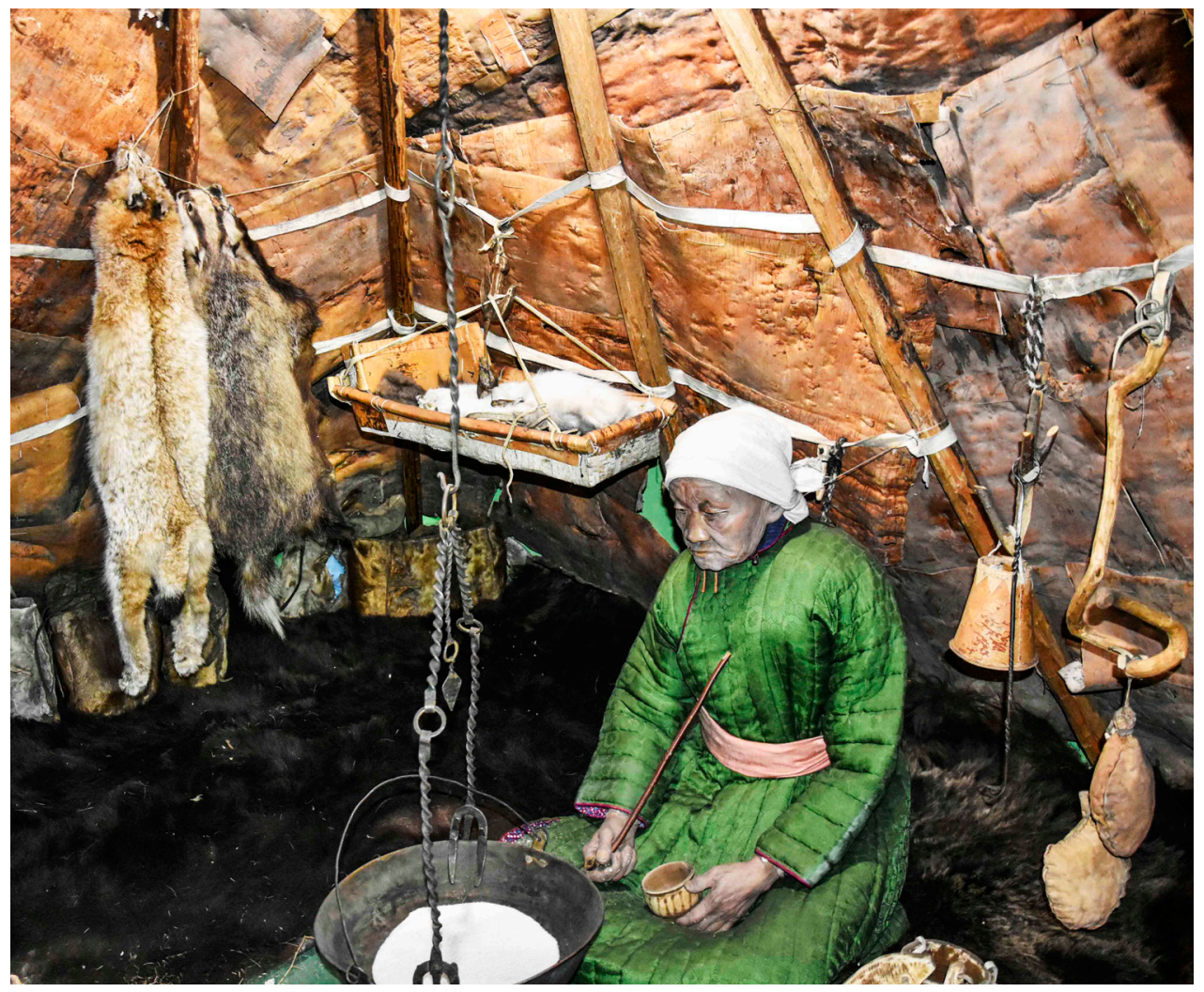

Фото 3. Детская колыбель (КП 10749/68), изготовленная А. М. Сундуй-оолом. Экспозиция «Тайга: в единстве с природой». Фото А. Д. Куулар, 2019 г. Photo 3. A cradle (KP 10749/68) made by A. M. Sundui-ool. Exposition «Taiga: in unity with nature». Photo by A. D. Kuular, 2019. 
НОВЫЕ ИССЛЕДОВАНИЯ ТУВЫ

www.nit.tuva.asia

\section{THE NEW RESEARCH OF TUVA}

Novye issledovaniia Tuvy

Таблица 2. Сведения о поступлениях колыбелей в коллекцию научно-вспомогательного фонда Национального музея Тувы (1976-2015 г2.) Table 3. Cradles in the research collection of the National Museum of the Republic of Tuva (acquired 1976-2015)

\begin{tabular}{|c|c|c|c|c|}
\hline Номер по КП & Год поступления & ФИО сдатчика & $\begin{array}{c}\text { Место } \\
\text { приобретения }\end{array}$ & $\begin{array}{c}\text { Источники } \\
\text { комплектования }\end{array}$ \\
\hline 113 & 1976 г. & $\begin{array}{c}\text { Оюн Александр } \\
\text { Чорбаевич }\end{array}$ & $\begin{array}{c}\text { с. Чал-Кежиг } \\
\text { Тандынского } \\
\text { района }\end{array}$ & - \\
\hline 234 & - & - & - & $\begin{array}{c}\text { Сбор заведующей } \\
\text { Кочетовским филиалом } \\
\text { В. Е. Оюн }\end{array}$ \\
\hline $796 / 1$ & 1992 г. & $\begin{array}{c}\text { Шогжат Натпит- } \\
\text { оола }\end{array}$ & $\begin{array}{c}\text { г. Шагонар, Улуг- } \\
\text { Хемчикского } \\
\text { района }\end{array}$ & - \\
\hline $796 / 2$ & 1992 г. & $\begin{array}{c}\text { Шогжат Натпит- } \\
\text { оола }\end{array}$ & $\begin{array}{c}\text { г. Шагонар, Улуг- } \\
\text { Хемчикского } \\
\text { района }\end{array}$ & - \\
\hline $2130 / 1,2$ & 2015 г. & & & $\begin{array}{l}\text { К. С. Донгак, зав. Алдан- } \\
\text { Мадырского филиалом }\end{array}$ \\
\hline
\end{tabular}

\section{Изучение колыбелей}

В русском языке слово «колыбель» имеет синонимы - «люлька» или «зыбка». Последнее слово «зыбка» по отношению к тувинскому кавай зафиксировано в Книге поступлений Красноярского краеведческого музея согласно полевой описи, составленной во время экспедиции в Урянхай в 1913 г. В «Толковом словаре тувинского языка» слово кавай имеет четыре значения: «1. Колыбель, люлька (чаш уруг чыттырар бичии орун). 2. Русло, долина реки (хемниң уну). 3. Коляска (кожар тергежигеш, кожак). 4. Гроб (кара)» (Толковый словарь тувинского языка, 2011: 13; курсив источника. - М. Д., А. Д.). Соответственно мы говорим о первом значении слова.

Слово кабай встречается у алтайцев и теленгитов (Хомич, 1988: 39). З. Б. Чадамба сопоставляла тувинский кавай с древнетюркским кабай, основываясь на чтении енисейских рунических памятников С. Е. Маловым (Чадамба, 1974: 20-21). Б. И. Татаринцев в своем фундаментальном исследовании этимологии тувинского языка, ссылаясь на 3. Б. Чадамба, добавил, что, действительно, слово, читаемое как кабай, отмечено в тексте памятника Е-41. Однако толкование его как названия колыбели небесспорно (Татаринцев, 2004: 23).

Кавай является аккумулятором социальной памяти, и он должен быть изучен в контексте культуры, т.е. расшифрован (Решетников, 2000: 101). Изучение музейных коллекций является основным направлением музейных исследований (фото 4).

В Национальном музее РТ на каждый уникальный предмет основного фонда составляется научный паспорт или карточка научного описания, где содержатся основные сведения о Фото 4. Детская колыбель в юрте. Экспозиция «Мир тувинцев». Фото А. Д. Куулар, 2019 г. нем. На тувинские колыбели

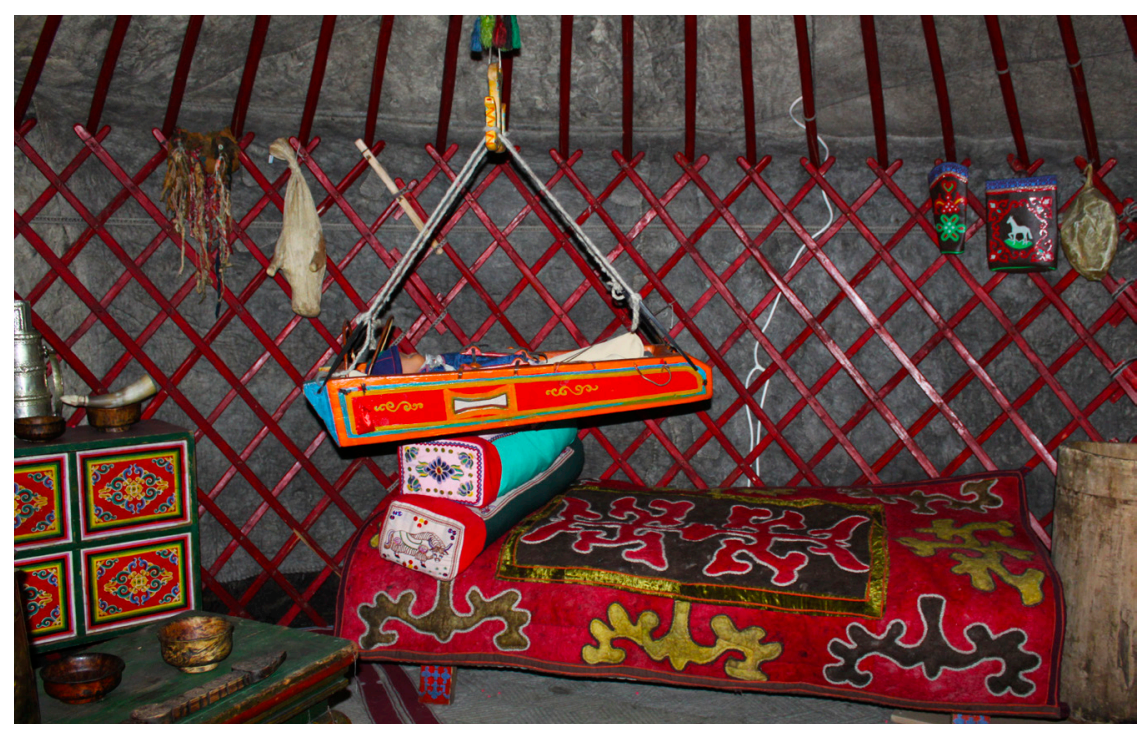
Photo 4. A cradle in the yurt. Exposition «World of Tuvans». Photo by A. D. Kuular, 2019. 
имеется 14 карточек с научным описанием, из них 10 - с номерами по КП основного фонда. До 1970 г. исследования фиксировались в научных паспортах, утвержденных Комитетом по делам культурнопросветительных учреждений при Совете Министров РСФСР. В них содержались следующие сведения о предмете: наименование, материал, количество, размер, покупная цена, способ поступления, техника изготовления, степень сохранности, датировка, подробное описание предмета, дополнительные сведения, ссылка на литературу, отметки о происходящих изменениях, подпись составителя и директора, дата составления паспорта. В паспорте должна содержаться фотография предмета и инвентарный номер.

15 сентября 1958 г. главным хранителем музея Т. Скаковой изучен кавай № 3114. Этот предмет недостаточно был исследован, т. к. не указана порода дерева при изготовлении колыбели, его размер, не уточнена техника работы, степень сохранности. Отсутствует полное описание, хотя составитель пыталась указать некоторые детали колыбели на тувинском языке. На паспорте отсутствует фотография предмета. Зато были известны фамилия, имя и отчество сдатчика - Хертек Хорлуу Мандан уруу, возраст 54 года, место ее рождения - с. Кара-Холь.

В 1971 г. в Тувинском республиканском краеведческом музее был введен новый образец научного паспорта, где появились новые разделы - автор, дата и источник поступления (вместо способа поступления), искусствоведческий и литературный комментарии. Были добавлены подписи составителя паспорта и главного хранителя. Сведения о колыбели под вышеназванным номером были переписаны главным хранителем Т. С. Нурзат, но она оставила без внимания сведения Т. Скаковой.

Изучив имеющиеся записи в этих документах, можно сделать вывод о том, что почти все они также имеют неполные данные, не хватает авторства, датировки, даты и источника поступления, отметки о сохранности.

Почему-то на один и тот же предмет - кавай под номером 5823, 3114 имеются два научных паспорта. Первый был составлен 30 ноября 1973 г. Е. Ш. Байкара, второй - Т. С. Нурзат 28 февраля 1980 г. Зато первая вместо описания ввела краткую легенду предмета, а вторая - его краткое описание.

В 1984 г. согласно инструкции по учету и хранению музейных ценностей, находящихся в Государственных музеях СССР, вместо «научного паспорта» была введена новая форма карточки научного описания. На первой странице документа необходимо стало указывать наименование музея, отдел, куда должен входить предмет. Добавлены 5 разделов, где надо было написать номер инвентаря, раздел по классификации, старый номер инвентаря, номер по КП, номер негатива, время и документ поступления.

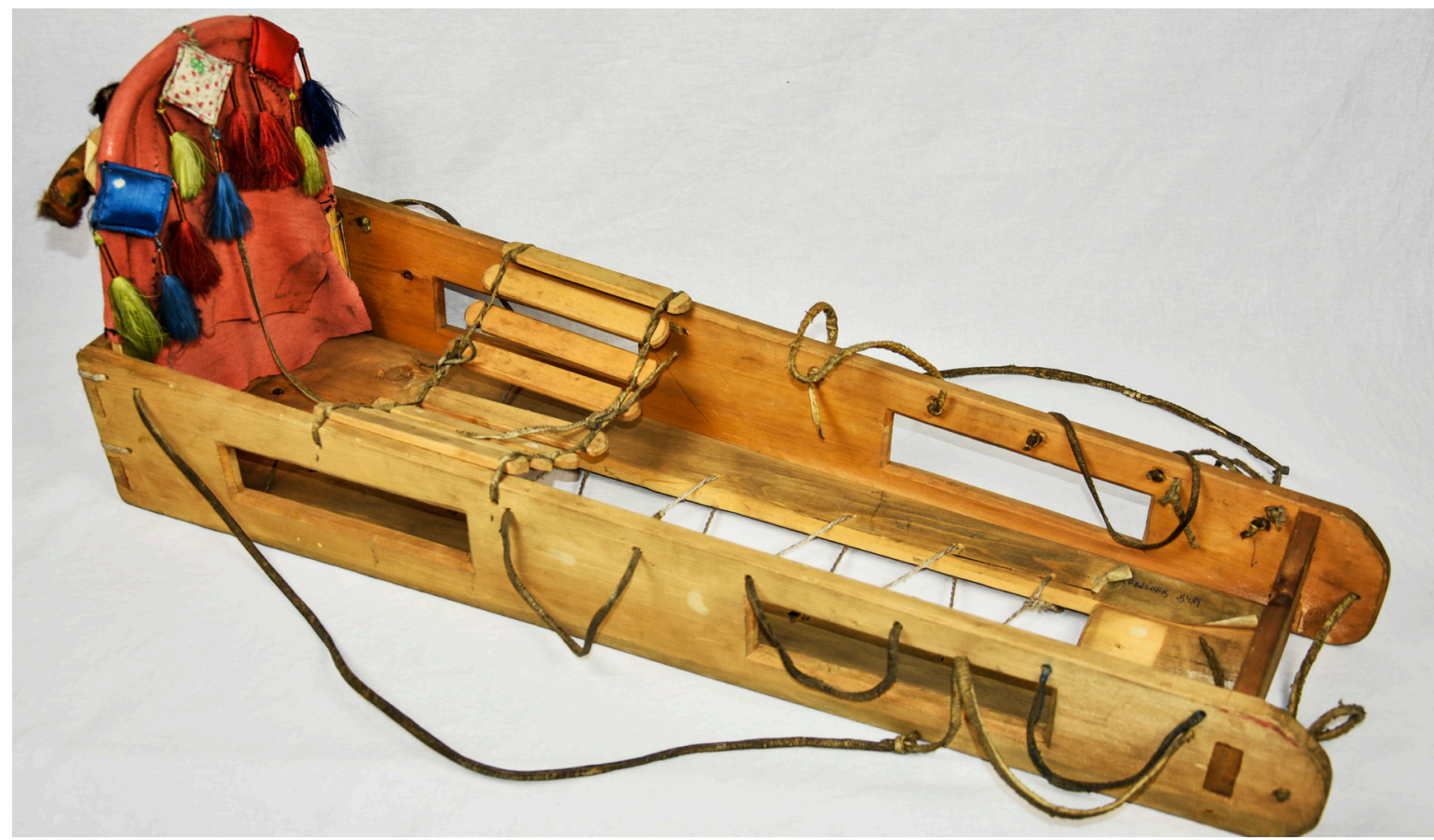

Фото 5. Детская кольбель, новодел. Автор неизвестен. Год поступления неизвестен (инв. 225). Фото А. Д. Куулар, 2019 г. Photo 5. A recently-made cradle. Master unknown, acquiry date unknown (Inv. No. 225). Photo by A. D. Kuular, 2019. 
Авторство уточняется, т. е. необходимо указывать мастера, страну, изготовителя, издателя или этническую группу. На 2-й странице должно быть полное описание предмета с его основными частями, обрамления. Указывается реставрация и консервация, публикации, использование или бытование, музейное значение, местонахождение предмета, отметка о выдаче и дата составления. Должны быть подписи составителя и директора.

Как гласит карточка научного описания, несмотря на то, что кавай под номером 10133/4 был приобретен в 1962 г. во время этнографической экспедиции в Бай-Тайгинском районе, он был зарегистрирован в КП 14 сентября 1993 г. Научное описание детской люльки оленеводов было составлено сотрудником музея Л. К. Монгуш в 2003 г. Здесь имеется более полное описание с указанием некоторых деталей и способ использования в домашнем быту. Однако составитель не указала музейное значение. Запись имеется на колыбель западных тувинцев под номером 10184, произведенная также Л. К. Монгуш.

На одной колыбели, являющейся новоделом, имеется оберег в виде трех квадратных разноцветных подушечек (фото 5). Раньше тувинцы в них хранили пуповину ребенка. Их количество указывало на то, сколько детей было в семье. Подробные детали колыбели описаны М. Б. Кенин-Лопсаном (Кенин-Лопсан, 2006: 163-168).

\section{Колыбель - транслятор этничности}

В экспозициях музея используется комплексный подход, позволяющий погружать посетителей в иное культурное пространство, приобщать их к историческому опыту этносов (Романова, 2010: 16). Приобщение к быту тувинцев помогает реконструкция традиционного жилища (у западных тувинцев войлочная юрта, у восточных - чум) с полным внутренним убранством. В его состав входит тувинская кровать и висящая над ней колыбель на женской половине жилища.

Этнографические памятники, отражающие мир детства, насыщенно и наглядно представлены на стационарной выставке «Мир детства у тувинцев», созданной в 2004 г. В экспозиции есть разделы «Дети в обычаях и обрядах тувинцев», «Трудовое воспитание в семье», «Трансформация элементов системы социализации в тувинском обществе». В том числе посетители смогли увидеть подушку для хранения пуповины ребенка, его первые пеленки - мягкие шкурки ягнят, две колыбели - из бересты тоджинских оленеводов и из дерева западных тувинцев. Экспонировались различные амулеты - обереги, которые привязывались тувинцами к колыбели или на стенку юрты, куклы, игрушки из природных камней, бараньи кости - астрагалы, комплекс детской одежды (Дыртык-оол, 2005: 106-110).

В 2015 г. в музее создана выставка «Хранитель ценностей и традиций», посвященная 90-летию со дня рождения ветерана музея, доктора исторических наук М. Б. Кенин-Лопсана. Научная концепция разработана одним из соавторов данной статьи - А. О. Дыртык-оол. Целью создания выставки стал рассказ о жизни и творческом пути этнографа. В разделе «Семья и семейные отношения в исследованиях ученого» экспонировались этнографические предметы, в том числе колыбель. Сквозная мысль фрагмента семейные традиции и обычаи тувинцев, обряды и ритуалы по отношению к колыбели. В данном случае здесь использовался образно-сюжетный метод.

Потенциал музея, а именно его этнографические коллекции, в том числе колыбели, широко используются в культурно-образовательных и просветительских мероприятиях учреждения, которые можно проводить на фоне выставок и экспозиций. В 2010 г. в музее было разработано специальное занятие для будущих матерей, где в центр внимания помещается колыбель. Сотрудник музея приводит интересную информацию по описанию в сравнении с другими сибирскими народами. Тут же демонстрируются древние ритуалы и обычаи, связанные с люлькой. До слушателей наглядно доводятся наставления М. Б. Кенин-Лопсана о том, тувинцы очень бережно относились к колыбели ребенка, никогда грубо не клали ее на землю, считая, что такое обращение с колыбелью приведет к тому, что душа ребенка может покинуть тело. Колыбель считалась первым «гнездом» для ребенка, появившегося на свет, местом, где он спит, отдыхает и растет. Поэтому тувинцы никогда не ломали колыбель своего ребенка, считая ее священным предметом (Кенин-Лопсан, 2006: 6). Надо подчеркнуть распространенность подобного представления в культурах. Русские также считали колыбель (зыбку) первым «домом» младенца. По словам В. В. Головина, зыбка имеет аналогии с гнездом, имеет защитные границы, проводится специальный ритуал укладывания ребенка (Головин, 2001: 36-38). Специальный обряд пеленания новорожденного ребенка у монголов и укладывания его в колыбель упоминается в книге Т. Намжила (Намжил, 2017: 116-117). 
НОВЫЕ ИССЛЕДОВАНИЯ ТУВЫ

www.nit.tuva.asia

Большую роль в культурно-просветительной работе музея играют его тесные контакты со школами и детскими учреждениями. Традиционно используются лекции с элементами беседы по популяризации историко-культурного наследия народов Тувы. Среди них можно выделить «Кавай как традиционная и духовная культура тувинцев», слушателями которого являются дети дошкольного возраста и школьники.

\section{Заключение}

Таким образом, собрание колыбелей западных и восточных тувинцев в Национальном музее Республики Тыва представляет собой исторический источник большой научной ценности. Колыбели, как и все этнографические предметы, собирались с целью сохранения для последующих поколений. Широкое использование этнографических предметов как вещественных источников, привлекающих внимание посетителей своей репрезентативностью и информативностью, превращает экспозицию в один из способов приобщение детей к богатой традиционной культуре своего народа.

В дальнейшем в планах работы отдела истории музея создание каталога «Детская колыбель как этнографический источник тувинского народа». В перспективе организация новых обучающих мероприятий, связанных с колыбелью - для девушек старших классов или студенток. Планируется культурно-образовательная программа «Кавай - священная вещь наших предков», состоящая из таких тем, как: «Виды колыбелей у тувинцев», «Обряд укладывания ребенка в колыбель», «Амулеты и обереги для ребенка», «Колыбель в устном народном творчестве».

\section{СПИСОК ЛИТЕРАТУРЫ}

Головин, В. В. (2001) Организация пространства новорожденного // Родины, дети, повитухи в традициях народной культуры / отв. ред. С. Ю. Неклюдов. М. : Российск. гос. гуманит. ун-т. 319 с. С. 31-60.

Дыртык-оол, А. О. (2014) Тувинская коллекция Ф. Я. Кона в Минусинском краеведческом музее им. Н. М. Мартьянова // Наука вчера, сегодня, завтра : сборник статей по материалам XV Международной научной конференции (6 октября 2014 г., г. Новосибирск) / отв. ред. А. И. Гулин. Новосибирск : СибАК. 102 с. С. 54-57.

Дыртык-оол, М. О. (2005) Мир детства в экспозиции Национального музея имени Алдан-Маадыр Республики Тыва// Музей в XXI веке: проблемы и перспективы : материалы Международной научно-практической конференции. г. Кызыл, 21-24 сентября 2005 г. / отв. ред. К. А. Бичелдей. Кызыл: КЦО «Аныяк». 156 с. С. $106-110$.

История Тувы (2016): в 3 т. / под ред. В. А. Ламина. Новосибирск: Наука. Т. 3.455 с.

Кенин-Лопсан, М. Б. (2006) Традиционная культура тувинцев. Кызыл: Тув. кн. изд-во. 230 с.

Мастеница, Е. Н. (2002) Информационный потенциал музейного предмета: этнокультурный аспект // Музей. Традиции. Этничность. XX-XXI вв. Материалы Международной научной конференции, посвященной 100-летию Российского этнографического музея / отв. ред. А. Б. Островский. СПб.; Кишинев: Nestor-Historia. 414 с. С. $328-330$.

Решетников, Н. И. (2000) Музееведение. М.: МГУКИ. 256 с.

Романова, Н. М. (2010) Принципы показа этнографических материалов в экспозициях краеведческих музеев. СПб.: Издательский Дом «ГАМАС». 192 с.

Смелякова, А. В. (2009) Этнокультурное наследие как ценность: аксиологический подход // Мир науки, культуры, образования. № 2 (14). С. 102-105.

Татаринцев, Б. И. (2004) Этимологический словарь тувинского языка. Новосибирск: Наука. Т. 3. 440 с.

Толковый словарь тувинского языка (2011): в 3 т. / под ред. Д. А. Монгуш. Новосибирск: Наука. Т. 2 (К-С). 798 с.

Устав Международного совета музеев (ИКОМ), принят на 16-й Генеральной Ассамблее ИКОМ (Гаага, Нидерланды, 5 сентября 1989 г.) с дополнениями и изменениями (Париж, Франция, 9 июня 2017 г.) [Электронный ресурс] // ИКОМ России. URL: http://icom-russia.com/upload/documents/Устав\%20ИКОМ_2017.pdf (дата обращения: 05.01.2019).

Хомич, Л.В.(1988) Колыбель у народов Сибири (к вопросу типологии) // Материальная и духовная культура народов Сибири. Сборник Музея антропологии и этнографии. Выпуск XLII / отв. ред. Р. Ф. Итс. Л. : Наука, Ленинградское отделение. 209 с. С. 24-49.

Чадамба, 3.Б. (1974) Тоджинский диалект тувинского языка. Кызыл: Тувинское книжное издательство. 136 с.

Шелегина, О. Н. (2014) Этнокультурное наследие белорусов в музее Сибири: результаты и перспективы актуализации // Гуманитарные науки в Сибири, № 1. С. 60-64.

Намжил Т. (2017) Монгол гэр булийн нэвтэрхий тайлбар толь. Улаанбаатар: БИТ ПРЕСС ХХК. 200 х. (На монг. яз.).

Дата поступления: 01.03.2019 2. 


\section{REFERENCES}

Golovin, V.V. (2001) Organizatsiia prostranstva novorozhdennogo [The organization of the space of the newborn]. In: Rodiny, deti, povituhi $v$ traditsiiah narodnoj kul'tury [Motherland, children, midwives in the traditions of folk culture] / ed. by S. Yu. Neklyudov. Moscow, Rossiisk. gos. gumanit. un-t. 319 p. Pp. 31-60. (In Russ.).

Dyrtyk-ool, A. O. (2014). Tuvinskaya kollektsia F.Y. Kona v Minusinskom krayevedcheskom muzeye imeni N.M. Martyanova [F.Y. Kon's Tuvan collection at the Minusinsk Museum of Local History]. In: Nauka vchera, segodnya, zavtra [Science yesterday, today and tomorrow] : proceedings of the 16th International Conference. / Ed. by A. I. Gulin. Novosibirsk, SiBAK. 102 p. Pp. 54-57. (In Russ.).

Dyrtyk-ool, M. O. (2005) Mir detstva v ekspozitsii Natsional’nogo muzeia imeni Aldan-Maadyr Respubliki Tyva [The world of childhood in the exposition of the Aldan-Maadyr National Museum of the Republic of Tuva]. In: Muzey v XXI veke: problemy i perspektivy [Museum in the 21st century, its problems and prospects]: proceedings of an international conference / ed. by K. A. Bicheldei. Kyzyl, Education Center of Aniyak. 156 p. Pp. 106-110. (In Russ.).

Istoriya Tuvy [The History of Tuva] (2016) : in 3 vol. / ed. by V. A. Lamin. Novosibirsk, Publ. Nauka. Vol. 3. 455 p. (In Russ.).

Kenin-Lopsan, M.B. (2006) Traditsionnaya kul tura tuvintsev [Traditional Culture of Tuvans]. Kyzyl, Tuvan publishing house. 230 p. (In Russ.).

Mastenitsa, Y. H. (2002). Informatsionnyi potentsial muzeynogo predmeta: etnokul turniy aspekt [Infromation potential of the museum subject: the ethnocultural aspect]. In: Muzey. Traditsii. Etichnost ' XX-XXI veka [Museum. Traditions. Ethical aspect. 20th-21st centuries]: proceedings of an international conference dedicated to the centenary of the Russian Ethnographic Museum / ed. by A. B. Ostrovskii. St. Petersburg, Kishinev, Nestor-Istorya. 414 p. Pp. 328-330. (In Russ.).

Reshetnikov, N. I. (2000) Muzeyevedeniye: kurs lektsii [Museum studies: a course of lectures]. Moscow, MSUCA Publ. 256 p. (In Russ.).

Reshetnikov, N. I. (2013) Muzey i komplektovaniye yego sobraniya [Museums and acquisition policy]. Moscow, MSUCA Publ. 160 p. (In Russ.).

Romanova, N. M. (2010) Principy pokaza etnographicheskikh materialov v ekspoziciyakh krayevedcheskikh muzeyev [Principles of displaying ethnographic materials in exhibitions of local history museums]. St. Petersburg, GAMAS Publ. 192 p. (In Russ.).

Smeliakova, A. V. (2009) Etnokul'turnoie naslediie kak tsennost': aksiologicheskii podkhod [Ethnocultural heritage as a value: an axiological approach]. Mir nauki, kul'tury, obrazovaniya, no. 2, pp. 102-105. (In Russ.).

Tatarintsev, B. I. (2004) Etimologicheskiy slovar` tuvinskogo yazyka [An etymological dictionary of the Tuvan language]. Novosibirsk, Nauka Publ. Vol. 3. 440 p. (In Russ. and Tuv.).

Tolkovyi slovar ` tuvinskogo yazika [A dictionary of the Tuvan language] (2011) : in 3 vols. / ed. by D. A. Mongush. Novosibirsk, Nauka Publ. Vol. 2. 798 p. (In Russ. and Tuv.).

Ustav Mezhdunarodnogo soveta muzeev (IKOM), priniat na 16-i General'noi Assamblee IKOM (Gaaga, Niderlandy, 5 sentiabria 1989 g.) s dopolneniiami i izmeneniiami (Parizh, Frantsiia, 9 iiunia 2017 g.) [Charter of the International Council of museums (ICOM), adopted at the 16th General Assembly of ICOM (the Hague, the Netherlands, September 5, 1989) with additions and changes (Paris, France, June 9, 2017)]. IKOM Rossii [online] Available at: http://icom-russia.com/upload/documents/Устав\%20ИКОМ_2017.pdf (access date: 05.01.2019). (In Russ.).

Khomich, L. V. (1988). Kolybel' $u$ narodov Sibiri (k voprosu tipologii) [Cradle among the peoples of Siberia: the issues of typology]. In: Material naya i dukhovnaya kul tura narodov Sibiri: Muzey antropologii i etnografii [Material and spiritual culture of the peoples of Siberia: Museum of Anthropology and Ethnography]. Vol. XLII / ed. by R. F. Its. Leningrad, Nauka, Leningradskoe otdelenie. 209 p. Pp. 24-49. (In Russ.).

Chadamba, Z. B. (1974) Todzhinskiy dialekt tuvinskogo yazyka [Todzhu dialect of Tuvan language]. Kyzyl, Tuvan book publisher. 136 p. (In Russ.).

Shelegina, O. N. (2014) Etnokul'turnoe nasledie belorusov v muzee Sibiri: rezul'taty i perspektivy aktualizatsii [Ethnocultural heritage of Belorussians in Siberia's museums: outcomes and prospects of actualization]. Gumanitarnye nauki v Sibiri, no. 1, pp. 60-64. (In Russ.).

Namzhyl, T. (2017) Mongol ger buliin nevterkhii tailbar tol'. Ulaanbaator, BIT press XXK. 200 p. (In Mong.).

Submission date: 01.03.2019. 